\title{
COSTA RICA'S INTRODUCTION OF PERIODIC TECHNICAL INSPECTIONS: AN ECONOMIC ASSESSMENT
}

Wolfgang H. Schulz, Zeppelin University, Germany

Sebastian Scheler, Zeppelin University, Germany

dx.doi.org/10.18374/JABE-20-3.12

\begin{abstract}
This paper investigates the effects on traffic safety and the associated economic savings of the introduction of RITEVE, the Periodic Technical Inspections (PTI) in Costa Rica. Since there were no national estimates for the costs of crashes in Costa Rica available, this study derives and evaluates in a first step different ways to estimate these costs. Subsequently these are used for a cost-benefit analysis to benchmark the policy decision to introduce periodic technical inspections. The findings show that there are considerable economic gains from having such a system in place with high cost-benefit ratios. The study shall give insights and encourage other countries to introduce or consider such measures as they can be an important step toward more road safety and reduce the cost of crashes for society and the economy.
\end{abstract}

Keywords: periodic technical inspection, Costa Rica, cost-benefit analysis, crash-cost estimates, willingness-to-pay 